\title{
Unidades fraseológicas en el español limeño: Investigación lingüística e inventario para la enseñanza de la lengua ${ }^{1}$
}

\section{Phraseological Units in Limeño Spanish: Linguistic Research and Inventory for the Teaching of the Language}

\author{
Rómulo F. Quintanilla Anglas \\ Dpto. Académico de Lingüística \\ CILA-FLCH-UNMSM \\ rquintanillaa@unmsm.edu.pe
}

\author{
Manuel E. Conde Marcos \\ Dpto. Académico de Lingüística \\ CILA-FLCH-UNMSM \\ mcondem@unmsm.edu.pe
}

\section{Resumen}

El presente artículo expone los resultados de una investigación realizada en el año 2017 en la ciudad de Lima sobre las denominadas unidades fraseólógicas (UUFF), un tema dentro del campo de estudio de la fraseología, que en nuestro país es poco explorado.

La investigación contempla dos partes claramente diferenciadas: en la primera parte, se describe la estructura, la función sintáctica y los contenidos semánticos de las unidades fraseológicas registradas, esto es, se las analiza lingüísticamente como parte de un sistema, considerando los componentes de este. La segunda parte de la investigación contempla la presentación de una relación organizada alfabéticamente de unidades fraseológicas usadas en la ciudad de Lima, que constituye la base de un futuro diccionario fraseológico de esta región. Adicionalmente, se presenta algunas pautas para el empleo de este listado de UUFF en la enseñanza de la lengua española.

Palabras clave: fraseología, unidad fraseológica, colocación, frase hecha paremia, diccionario fraseológico

\begin{abstract}
In this paper, the results of an investigation carried out in 2017 in the city of Lima on so-called phraseological units (PU) are presented, a topic inside of the field of study of Phraseology, which is little explored in our country.

The study is presented in two clearly differentiated parts: in the first part, the structure, the syntactic function and the semantic contents of the registered phraseological units are described, that is, they are linguistically analyzed as part of a system, considering its components. The second part is a presentation of an alphabetically organized list of phraseological units (PU) used in the city of Lima, which forms the basis of a future phraseological dictionary of this region. Additionally, some guidelines for the use of this list of UUFF in the teaching of the Spanish language are presented.
\end{abstract}

Keywords: Phraseology, phraseological unit, collocation, a catch-phrase, paremia, phraseological dictionary

1 Proyecto desarrollado por el Grupo de Investigación «Gramática Descriptiva (GRAmDE)». UNMSM, VRI, 2017, Código: E17030931 


\section{Introducción}

Las lenguas naturales, consideradas sistemas, "producto social del lenguaje», (Saussure, 1916), esto es, en su función primordial como medio de comunicación humana, presentan diversos aspectos que meritoriamente son objetos de estudio sistemático. Uno de estos fenómenos lingüísticos, por mucho tiempo soslayado en los estudios gramaticales de las lenguas naturales, fueron las ahora llamadas unidades fraseológicas (UUFF), las frases hechas y las paremias que comprenden algunas variedades de unidades fraseológicas.

Se entiende por fraseología a la disciplina lingüística que se ocupa de estudiar expresiones denominadas unidades fraseológicas. La literatura sobre el tema da cuenta de trabajos detallados sobre diversos aspectos que ofrecen las unidades fraseológicas en la lengua español. Ello comprueba su presencia y uso en las lenguas estudiadas hasta el momento. El valioso aporte de estas unidades se manifiesta como un recurso de comunicación, sobre todo, oral. Los estudios realizados se refieren a aspectos estructurales (morfológicos), sintácticos y semánticos. Respecto al primer aspecto, las mencionadas unidades se forman con más de una palabra, generalmente, con el valor de una unidad léxica simple. La posición de las unidades que las conforman, en la mayoría de los casos, es fija, esto es, las palabras que las constituyen conservan una posición estable y, además, no pueden ser sustituidas por otras; de intentarse modificar estos aspectos, se correría el riesgo de formar unidades ininteligibles o con significados distintos a los que se desea transmitir en la comunicación. A la pérdida de precisión, se sumaría la pérdida del matiz expresivo que caracteriza a estas unidades idiosincrásicas de la lengua española.

En la actualidad, tales unidades se han ganado la atención de los estudiosos (debido a la frecuencia con que se usan), muchos de los cuales ya las consideran importantes objetos de estudios sistemáticos. Las unidades fraseológicas (UUFF) son estudiadas como temas centrales de tesis, se publican artículos, se presentan ponencias en certámenes académicos, etc., hechos que clamar por su inclusión en los programas curriculares escolares y universitarios.

En nuestro medio, apenas se ha empezado a considerar dicho fenómeno lingüístico ${ }^{2}$, sobre todo, en congresos nacionales de lexicografía. Las UUfF que se describen son generalmente del español y del quechua. Las características que

2 El año 2004, Rómulo F. Quintanilla Anglas presentó a la Facultad de Letras y Ciencias Humanas de la unMSM un proyecto referido al tema con el título «Las frases hechas en el español» (que desarrolló durante el Año Sabático que usó).

100 Lengua y Sociedad 
han llamado más la atención de los investigadores, es el valor de léxico que tienen y el matiz expresivo que encierran.

Por ejemplo, «a pedir de boca» equivale al adjetivo «agradable», pero con el superlativo valor agregado «muy agradable» (a la vista, incluso al gusto de alguna comida). Otro de los aspectos que llama la atención de estas unidades es su carácter expresivo, que puede observarse en ejemplos como el siguiente: una UF usada en el habla juvenil es «tirar arroz», como en «Julia le tiró arroz a Pablo»; no se trata de lanzar algo (p. e. granos de arroz); el significado con que se expresa esta UF es "despreciar»', pero con un matiz intensivo, generalmente despectivo; usando otras unidades fraseológicas sinónimas se diría que «lo dejó mal parado» o lo «avergonzó» negándole algún pedido.

Considérense, por ejemplo, las UUfF siguientes: 1. «metió la cuchara», 2 «metió la pata», 3 «metió miedo», 4. «metió la mano», etc. Se observa que expresan significados diferentes de uso bastante común en la ciudad de Lima. En ninguna de estas unidades se puede cambiar el término «metió», por ejemplo, por «introdujo»; hacerlo conduciría a la pérdida del sentido del mensaje que se desea transmitir $y$, en última instancia, de entenderse por alguna razón, perdería la fuerza elocutiva, la expresividad y otros matices que las caracterizan. Los significados con los cuales se transmiten las mencionadas UUFF, respectivamente, son: 1. 'Intervenir en una conversación inoportunamente'; 'intervenir sin ser invitado a ello'; 2. 'equivocarse', 'fallar'; 3. 'causar susto', 'amenazar'; 4. 'sustraer', 'apropiarse de algo ajeno (generalmente de dinero sistemáticamente sustraído)'. Obsérvese que no significan lo, mismo «meter la pata» $\mathrm{y}$ «meter la mano», a pesar de que 'mano' y 'pata' son cohipónimos del hiperónimo «extremidad».

El uso frecuente de estas unidades en la comunicación oral (algunas ya están apareciendo en la comunicación coloquial escrita), prácticamente en todos los niveles sociales, no hace sino corroborar su importancia como valiosos recursos de comunicación, básicamente oral.

Las unidades fraseológicas creadas y usadas en la ciudad de Lima tienen, como en cualquier otra lengua, un carácter idiosincrásico; se revelan en ellas parte de la cultura y la influencia social que contribuyen a darles forma y dotarlas de significados claros y precisos, como se podrá apreciar más adelante. Podría afirmarse que es la frecuencia con que se usan, la influencia de determinadas variables sociales que caracterizan a los usuarios y otros factores relacionados con el uso lingüístico y la intención comunicativa los que abonan a favor de la creación de las mencionadas unidades y que justifican el aumento de la importancia que se 
les viene reconociendo en los estudios de la lengua; y difusión por parte de reconocidos investigadores. Su inclusión en los diversos programas curriculares de educación no haría sino reconocer la importancia de este fenómeno de la lengua española, pues las unidades denominadas frases hechas y otras son muy productivas en la comunicación.

El estudio comprende, además de las estructuras que presentan, la función sintáctica que cumplen y los significados (y sentidos) que expresan en «el uso real» de la lengua; ello, porque los procesos: forma (estructura) y función (significados) las cumplen dentro del sistema de la lengua española. El estudio se complementa con la presentación ordenada del material lexicográfico acopiado (base del futuro diccionario fraseológico de Lima).

\section{Metodología}

La investigación es, básicamente, de carácter descriptivo y teóricamente se enmarca dentro del funcionalismo, pues se considera que la lengua es prioritariamente un instrumento de comunicación. "Toda lengua es una estructura porque, en su conjunto y en sus partes constitutivas, funciona adecuadamente, esto es, cumple el fin para el que ha sido instituida: permitir la comunicación entre los humanos de una misma comunidad. Tanto vale así hablar de «lingüistica estructural» como de «lingüística funcional» (E. Alarcos (1977).

Puesto que toda gramática estructural es funcional, ya que el valor de un elemento lingüístico se halla, no tanto en lo que es en sí, sino en la relación que se establece entre ese elemento y el sistema en el que se integra, esto es, en la función que ese elemento desempeña en el sistema, en la forma en que se opone a los otros elementos del mismo sistema (Ver Saussure, 1916). Sin embargo, tales principios no funcionan de igual manera en la estructura interna de una frase nominal o verbal respecto a una unidad fraseológica (UF), puesto que las unidades que conforman una UF no funcionan sintácticamente respecto al otro u otros elementos que lo acompañan para formar las UU FF. Así, en la UF «Se fue de cara», las unidades Se+fue+de+cara no suman sus significados individuales para producir el significado «se llevó un chasco». Es distinta la relación que se establece entre las unidades que conforman una frase como «la casa grande» por ejemplo, donde «la» determina a «casa» y esta es calificada por «grande». En la 
UF, todas las unidades que la conforman se unen para significar algo y funcionar sintácticamente en boque.

Las diversas unidades fraseológicas registradas en el habla de los limeños tuvieron como fuente inicial hablas espontáneas que se grabaron en distintas circunstancias de comunicación; luego de la primera transcripción del material se seleccionaron algunas UUFF de mayor recurrencia que sirvieron para elaborar un primer cuestionario que fue aplicado a distintos hablantes. La investigación parte del acopio de información lingüística extraída de la llamada «lengua viva», esto es, de la lengua usada cotidianamente (algunos la llaman coloquial o popular). En ese afán, se amplía el concepto de función de la lengua, pues abarca aspectos no solo referidos a la sintaxis sino también a los contenidos semánticos con que se usan las unidades fraseológicas habladas en el español limeño.

\section{Universo del estudio}

El uso de las unidades fraseológica ha rebasado estratos sociales como los marcados por el género, por ejemplo, puesto que las usan hombres y mujeres con cierto porcentaje de diferencia a favor de los varones. Igualmente, parece que la educación (nivel) tampoco es una variable que señala una diferencia fija, pues existen unidades fraseológicas que son usadas sin distingo alguno: «acuchillar por la espalda», por ejemplo, es entendida por hombres y mujeres de distintas edades y grados de educación. De modo que el universo del presente estudio comprende hablantes de distinto género, edad, educación, ocupación, etc., que se irán precisando en el transcurso del trabajo.

\section{Técnicas usadas}

Previamente al proceso de acopio del material lingüístico, los miembros colaboradores, integrantes del GI «GRAMDE», fueron claramente informados sobre qué tipo de datos lingüísticos debían capturar y registrar (en frases, oraciones y aun textos). Con esa finalidad se recurrió a grabaciones, inicialmente espontáneas, cuyo resultado fue la base sobre la que confeccionó un cuestionario ad-hoc, que no solamente se usó para comprobar y añadir significados de las unidades fraseológicas acopiadas previamente, sino también para ampliar el número de 
UUFF. Varias entrevistas individuales (algunas veces grupales) corroboraron las funciones que cumplen estas unidades y los significados con las que se usan. Uno de los cuestionarios para comprobar el conocimiento y uso de las UUfF tenía el siguiente formato:

\section{Cuestionario}

Indicación: De los significados posibles con que se entiende la frase subrayada, marque con un aspa, el significado con el cual usted lo entiende y usa.

\section{A boca de jarro}

a) Impacto sobre algo a muy corta distancia ( )

b) Lanzar una jarra a la boca de una persona

c) Realizar alguna acción muy cerca de otra persona

d) No lo entiende

e) Otro significado:

\section{A pedir de boca}

a) Agradable a la vista o al gusto (p. e. una comida, persona, etc.......... ( )

b) Solicitar algo verbalmente

c) Solicitar algo vociferando o a gritos

d) No lo entiende.

e) Otro significado:

120 ítems semejantes fueron aplicados a informantes limeños y en sendas entrevistas personales, se comprobaron o se desechados cuando el uso de la uf era de uso muy restringido (o individual).

\section{Resultados}

La investigación contempla dos partes claramente diferenciadas: en la primera parte, se describe la estructura, la función sintáctica y los contenidos semánticos de las unidades fraseológicas registradas, esto es, se las analiza lingüísticamente como parte de un sistema, considerando los componentes de este. La segunda parte de la investigación contempla la presentación de una relación organizada alfabéticamente de unidades fraseológicas usadas en la ciudad de Lima. 


\section{Unidades fraseológicas en el español limeño}

\section{Morfología de la UUFF «frases hechas»}

En la lengua española, probablemente como en otras lenguas, existe varios tipos estructurales de unidades fraseológicas. Distinguirlas y caracterizarlas fue el afán que distrajo por mucho tiempo a los lingüistas. En la actualidad, la preocupación mayor que ocupa el quehacer lingüístico no es tanto las clases, sino las formas (combinaciones) que presentan y los contenidos semánticos con los cuales se usan tales unidades.

Las UUFF usadas en Lima son, básicamente, las denominadas frases hechas $y$ paremias. La paremia - señala Gloria Corpas (1983) - es un enunciado breve, sentencioso e ingenioso, transmite mensaje instructivo que incita a la reflexión intelectual y moral. Los tipos de paremias que se usan en español son los adagios, los aforismos, los axiomas, los proverbios, los refranes y los dialogismos. De ellos, se suele señalar a los refranes como el tipo más común de paremia.

\subsection{Estructura de la UF}

La unidad fundamental, objeto del presente estudio, es la unidad fraseológica (UF) considerada «frase hecha». Como toda unidad fraseológica, está constituida por un grupo de unidades léxicas, que pueden estar conectadas entre sí por unidades funcionales o gramaticales como artículo, preposición o conjunción, las cuales en conjunto dotan de significado a las UUFF (nos comunicamos a través de significados). Las combinaciones de estas unidades son diversas, por ello, las iremos señalando, seguida del valor léxico que expresan y de la función sintáctica que cumplen.

Como se señaló en líneas anteriores, los elementos que estructuran una UF, en la gran mayoría de los casos, conservan una posición fijan y son irremplazables. Por ejemplo, en "hoy quiero beber hasta morir» no podría combinarse para dar * «hasta beber morir quiero». Si el cambio de orden atenta contra el significado deseado, no es menos obvio que los elementos que la constituyen son insustituibles. Así, se observa en UUFF como «estirar la pata» (fallecer), donde las unidades que la forman no podrían sustituirse por otras, por ejemplo, con «estiró el pie o la pierna», hacerlo, produciría una combinación que tiene otro significado.

Se puede identificar UUFF aludiendo a algunas características que menciona Gloria Corpas Pastor: «Las unidades se dividen en aquellas que constituyen actos de habla completos y aquellas que no lo son, esto es, un factor que se combina con 
las particularidades paradigmáticas y sintagmáticas de las UUFF que vienen determinadas por la restricción. La fijación interna limita la elección paradigmática de los componentes, imponiendo restricciones en el inventario y en la inflexión interna de estos. Cada una de las esferas se subdivide, a su vez, en diversos tipos de uf en virtud de una serie de criterios adicionales: categoría gramatical, función sintáctica, carácter de enunciado, independencia textual, etc.» (Corpas Pastor 1997, p. 269).

De este modo, en el análisis se consideran las colocaciones (la posición de las unidades internas que estructuran una UF, los actos de habla no completos que se ciñen a las normas de la lengua, pero que tienen distinto grado de fijación según estas normas de uso; la restricción es menor en algunas clases de UUFF; son casos en que los elementos colocados permiten sustituciones paradigmáticas en diferentes grados, por ello presentan colocaciones libres, restringidas, estables y categorías puente, las cuales marcan la diferencia con unidades fraseológicas cuyos elementos presentan posición fija. La subdivisión en tipos de colocaciones se lleva a cabo basándose en la estructura interna, según las categorías gramaticales.

\subsection{Colocaciones.}

Las colocaciones constituyen una característica fundamental (en el modelo que seguimos) a tal punto que no se consideran como algo marginal, sino central en este tipo de trabajos. Veamos algunos ejemplos de G. Corpas Pastor (1997, p. 270):

1. $V+S$ (sujeto): correr un rumor, declararse un incendio.

2. $\mathrm{V}+$ (prep. +) $\mathrm{S}$ (objeto): asestar un golpe, poner en funcionamiento.

3. Adj./S + S: momento crucial, visita relámpago.

4. $S+$ prep. + S: banco de peces.

5. $\mathrm{V}+$ Adv.: negar rotundamente.

6. Adj. + Adv.: opuesto diametralmente.

A pesar de que las unidades que señalamos en mayor cantidad son las mencionadas frases hechas y algunas clases de paremias, se incluyen algunas unidades denominadas «locuciones»; ello, atendiendo a la frecuencia de su uso en la lengua española.

Corpas considera que las locuciones son actos de habla no completos, formados por combinaciones de palabras cuyo significado no es la suma semántica de sus componentes; tienen, por tanto, un carácter idiomático y frecuentemente son paradigmas cerrados. 


\section{Unidades fraseológicas en el español limeño}

\section{Ejemplos de locuciones}

1. Loc. Nominales: mosquita muerta, paño de lágrimas, el qué dirán

2. Loc. Adjetivas: corriente y moliente, más papista que el Papa, de rompe y rasga.

3. Loc. Adverbiales: gota a gota, de tapadillo, a raudales.

4. Loc. Verbales: llevar y traer, nadar y guardar la ropa, meterse en camisa de once varas.

5. Loc. Conjuntivas: antes bien, como si.

6. Loc. Cláusulas: salirle a alguien el tiro por la culata, como quien oye llover.

En estas clases tienen cabida las UUFF que constituyen actos de habla completos, paremias y fórmulas rutinarias. Las primeras pueden servir para convencer, persuadir e instruir al receptor, aunque cuando no se persigue reacción alguna, las paremias cumplen más bien una función fática. En cuanto a las fórmulas rutinarias, dado que son formas establecidas convencionalmente para realizar determinados actos de habla, se persiguen primordialmente fines sociales y facilitadores de la interacción. En su mayoría solo se limitan a constituir la expresión de sentimientos y actitudes canalizados socialmente o la realización verbal adecuada para encuentros «ritualizados». Su grado de fijación es menor que en las locuciones y las paremias (Corpas Pastor, 1997, pp. 272 y 275).

Según lo mencionado hasta el momento, una función sintáctica es la que cumplen unidades simples o grupales respecto a otras unidades simples o grupales con las cuales coaparecen en el enunciado. Por ejemplo, en una frase nominal como «las frases cortas», cada unidad que la constituye cumple una función sintáctica: el sustantivo «frases» funciona como núcleo respecto al artículo «las» y el adjetivo «cortas» que cumplen la función de modificadores del núcleo (o con respecto al núcleo). Una unidad fraseológica (UF) también puede cumplir semejantes funciones u otras, según sea el caso:

En un contexto como en «este plato está a pedir de boca», la estructura secuencial (colocación) de la UF es verbo copulativo (está) + preposición «a» + verbo «pedir» + preposición «de» + nombre «boca». Como el elemento al que está complementando es un nombre (plato), la mencionada Uf cumple la función sintáctica de complemento atributo; su significado es «muy agradable»con cierto matiz superlativo. 


\section{Semántica de las UF}

Como se mencionó líneas arriba, las UUfF expresan significados léxicos, sin embargo, algunas deben ser expresadas con dos o más palabras simples: la UF «a pedir de boca» se puede interpretar con una sola palabra que indica el contenido superlativo de dicha UF como «agradabilísimo» o con dos palabras «muy agradable». No se incluye estrictamente la observación de si una determinada UF forma parte del habla estándar o al habla popular; ello llevaría a observaciones con criterios más sociolingüísticos; el presente trabajo es lexicográfico. Sin embargo, en el transcurso del estudio se ha podido comprobar la existencia de casos de UUFF sinónimas y polisémicas. Así, «estar pelado» y «estar aguja» son UUFF sinónimas, significan «carecer de dinero»; «lengua larga» significa «hablador», «delator» (polisemia).

\section{Análisis lingüístico de las UUFF usadas en Lima}

1. UF: Agarrar de cholito (a alguien).

EsT. Colocación: V + Prep. $+\mathrm{S}$

SIG: 'Tomar el pelo de manera burlona y por tiempo prolongado, reiterativo'.

FUN: verbo $\rightarrow$ núcleo del predicado.

Ejemplo: José siempre agarra de cholito a su primo.

2. UF: Meter su cuchara.

EST. Colocación: $\mathrm{V}+$ Det. $+\mathrm{S}$

SIG: 'Intervenir abruptamente en una conversación sin ser invitado. Opinar sin base'.

FUn: Verbo $\rightarrow$ núcleo del predicado.

Ejemplo: Nunca deja de meter su cuchara en las conversaciones.

3. UF: Lavar el cerebro.

EST. Colocación: $\mathrm{V}+$ Det. $+\mathrm{S}$

SIG: 'Convencer totalmente, aun sin argumentos lógicos o reales'.

FUN: Verbo $\rightarrow$ núcleo del predicado.

Ejemplo: Le lavaron el cerebro a Susana. 
4. UF: Sacar los trapitos al sol.

EST. Colocación: $\mathrm{V}+$ Det. $+\mathrm{S}+$ Prep. $+\mathrm{S}$

SIG: 'Exponer o hacer público temas personales o muy particulares'.

FUn: Verbo $\rightarrow$ núcleo del predicado.

Ejemplo: Las chicas se sacaron los trapitos al sol ayer.

5. UF: Jugar con fuego.

EST. Colocación: V + Prep. + S

SIG: 'Actuar peligrosamente', 'mentir temerariamente'.

FUN: Complemento circunstancial de modo.

Ejemplo: Jugar con fuego te puede ocasionar malestares.

6. UF: Irse de lengua.

EST. Colocación: $\mathrm{V}+$ Prep. $+\mathrm{S}$

SIG: 'hablar de más'.

Ejemplo: Es tipo se fue de lengua frente al juez.

FUN: Complemento circunstancial de modo.

7. UF: De mal en peor.

EST. Colocación: Prep. + Adj. + Adj.

SIG: 'Mal o más grave'.

FUN: Complemento circunstancial de modo.

Ejemplo: El problema va de mal en peor.

\section{Discusión}

De la investigación, se puede inferir que conceptos como la llamada competencia lingüística o competencia gramatical de los hablantes se pone de manifiesto en la creación de distintas formas lingüísticas que se usan en el proceso de comunicación. Las unidades fraseológicas (UF) constituyen una de estas formas complejas que se apartan de lo que tradicionalmente fue la única preocupación de los estudios lingüísticos.

El estudio de las unidades fraseológicas que se usan en el español hablado en la ciudad de Lima es evidencia de que existen y que muchas de sus formas no tienen equivalencia exacta con formas simples como palabra: «lo tiene comiendo de su 
mano», por ejemplo, no se puede interpretar solo como «dominado», sino como «dominado totalmente sin capacidad para reaccionar o reclamar».

Por otro lado, los resultados del estudio permiten confirmar la gran competencia creativa de los hablantes. Se observa también, como lo han hecho otros autores, para el español de otras zonas y estudiosos de lenguas distintas a la española, que las UUFF tienen carácter idiosincrático, pues en muchos casos, tanto la colocación de sus unidades y sus significados son distintas dependiendo de la lengua a las que pertenecen.

Debemos suponer que las UUFF son productos sociales y culturales de la facultad humana del lenguaje, por ello, se vislumbra también casos de variaciones originadas por factores sociales y/o geográficos, por ejemplo, en el lenguaje coloquial español de la península, la UF «tirarse un pedo» significa 'embriagarse exageradamente'; no existe en el español de Lima.

\section{Conclusiones}

a) Las unidades fraseológicas (UF) constituyen unidades lingüísticas que se usan en la ciudad de Lima y, presumiblemente, en todo el Perú.

b) El uso de las uf ha rebasado estratos sociales, pues, a diferencia de creencias antiguas, estas no son solo de uso de iletrados o de personas «de estratos sociales muy bajos».

c) La creación de Uf es producto de la maduración gramatical lingüística de los hablantes, matizado con factores sociales, culturales, etc.

d) Los factores socioculturales originan la existencia de variedades regionales y sociales (dialectos y sociolectos) respectivamente.

e) La creación y uso de las uf es cada vez más frecuente. Acabamos de escuchar el uso de un neologismo fraseológico: «Él no mastica clavos» cuyo significado es «él no es tonto ni ingenuo».

f) En la ciudad de Lima, las unidades fraseológicas, generalmente son de carácter oral. Vienen ocupando espacio en la escritura, sobre todo, en el ámbito deportivo: "salir al campo con la sangre en los ojos», "con el cuchillo entre los dientes», etc., para indicar que los jugadores entraron al campo con 'nuevos bríos', 'con mayores deseos de ganar'. 


\section{Unidades fraseológicas en el español limeño}

\section{Recomendaciones}

1. En el proceso de comunicación interviene enunciados que están constituidos por unidades fraseológicas que coadyuvan a la comprensión del discurso tanto oral como escrito; por tanto, es recomendable que este tipo de unidades sean tema de estudio en los niveles de primaria y secundaria en la educación formal.

2. Se recomienda la publicación de trabajos de este tipo, así como su difusión por entidades educativas como ocurre en otros países como España, Cuba, Argentina y muchos otros.

\section{Breve vocabulario fraseológico Unidades fraseológicas usadas en el español limeño}

\section{Presentación}

Desde que Iñigo López de Mendoza publicara una breve relación de refranes en español (1512), formas que también fueron consideradas por Juan de Valdés (1621) como existentes en las lenguas clásicas (griego y latín), el interés por las unidades fraseológicas ha venido ganando campo; hoy los estudiosos (lingüistas y gramáticos) que se ocupan de la función primordial de las lenguas: la comunicativa, no pueden ya soslayar la importancia que este recurso comunicativo tiene para los hablantes pertenecientes a diferentes estratos socioeconómicos.

Las unidades fraseológicas no solamente se destacan por presentan estructuras diferentes a las históricamente identificadas como comunes o estándares en la lengua española, formas que por mucho tiempo fueron vistas como curiosidades y aun con desdén, como se desprende de las palabras de Iñigo López, quien consideraba a estas unidades como "refranes que dicen la viejas tras el fuego" o de Juan de Valdés que con el mismo desdén o desprecio señalaba que «los refranes del español son propio de gente ignorante» a diferencia de las griegas o latinas que eran hechas por gente «docta». En ellas subyace, además, el genio y la potencialidad creativa de los hablantes, reflejadas en las combinaciones de unidades que comunican con una fuerza expresiva que no poseen las formas simples.

El presente vocabulario (lexicón) es una versión preliminar de lo que, más adelante, pretende convertirse en un diccionario fraseológico del español hablado 
en el Perú, esto es, ser una obra de consulta sobre la existencia, significado y uso de este tipo de unidades lingüísticas.

El vocabulario constituye la segunda parte del estudio descriptivo sobre las estructuras y las funciones de las unidades fraseológicas habladas en la ciudad de Lima capital y en gran parte de los distritos que la conforman. Es un trabajo de carácter preliminar en el cual se incluyen unidades fraseológicas sin distingo de clases, pues el interés se ha centrado en comprobar su existencia y uso, determinar sus formas e identificar sus significados. El orden alfabéticamente en que se presentan pretende que sean entendidas por todo nivel de lectores $y$, de ese modo, facilitar su difusión en todos los niveles de centros educativos.

Puesto que es interés de los autores reunir la mayor cantidad posible de unidades fraseológicas, los lectores que conozcan algunas de estas unidades pueden hacer llegar sus opiniones sobre formas y significados y hacernos llegar algunas que escucharon o leyeron, mejor si son distintas a los que presentamos en este breve trabajo preliminar.

\section{Algunas pautas para el uso del vocabulario}

El registro de las unidades fraseológicas destinadas a la enseñanza de la lengua está dirigido a hablantes nativos del español y a extranjeros que desean aprender la lengua española en todas sus características formales y semánticas.

Las unidades se presentan en forma alfabética a partir de la letra donde empieza la unidad fraseológica, por ejemplo, «matar(se) de risa» se ubicaría en la sección que empieza con «m» (ma); «morir(se) de risa» (seguirían la secuencias ma, me, $\mathrm{mi}, \mathrm{mo}, \mathrm{mu}$ ).

Cuando se presentan sinónimos como «Dar la cara», «Poner el pecho» u otros, se colocan una después de la otra con el símbolo ídem entre paréntesis. Si una expresa semánticamente algo más que la otra (que las diferencie en alguna medida), se describe tal o tales significados añadiendo las precisiones.

a) Dar la cara

b) Poner el pecho

En el caso de existir polisemia, se colocan los significados en orden alfabético. 


\section{Unidades fraseológicas en el español limeño}

Salir el tiro por la culata. Verbo. Acción frustrante.

Conclusión adversa a la esperada.

Si bien, mayormente, las unidades fraseológicas equivalen a formas simples como de sol a sol «demasiado» o «mucho», el contenido semántico de muchas de estas unidades se trata de precisar con más de una palabra: está a pedir de boca equivale a un adjetivo, pero con el añadido de muy o bastante agradable ( a la vista o al paladar).

La estructura interna del vocabulario comprende el artículo (de qué se trata); seguidamente, a) el lema escrita en negrita; en ocasiones, parte del lema aparece entre paréntesis: «hacerle la camita (a alguien)», para indicar que se puede entender que también que «hacer la camita» no necesariamente a alguien, sino que puede tener un sentido genérico 'quitar la confianza', 'originar choques de conflicto', 'desestabilizar'; b) la o las acepciones, cuya entrada puede tener una o más acepciones incluidos los que tienen carácter metafórico como «cortarse las venas (por alguien)»; c) colocaciones o unidades distintas (de las partes), tal como se escuchó que se usan, siempre que no modifiquen los significados: En carne propia / en propia carne; Llegó con la cola (o rabo) entre las piernas. Cada acepción es ilustrada con uno o más ejemplos si la necesidad de aclaración o precisión lo amerita.

\section{Consideraciones generales}

La explicación sobre el origen de las fuentes de los datos, lo métodos empleados en el acopio, así como el ámbito o lugar (es) en los que se usan estas unidades fraseológicas ha sido presentadas líneas arriba en el apartado denominado Metodología. Cabe señalar aquí que en algunos ejemplos dialectales se han realizado comparaciones con las empleadas en otras zonas del español.

\section{Registro preliminar}

\section{A}

A boca de jarro: Adverbio. Impacto fuerte sobre un cuerpo desde una distancia muy cercana.

Afilar la puntería: Verbo. Prepararse bien para obtener el resultado que se desea. 
A pedir de boca: Adjetivo. Muy agradable o perfecto para la vista o el gusto A ojo de buen cubero: Verbo. Observación sobre algo o alguien que realiza un experto.

A la ligera: Verbo. Realizar un trabajo o revisar algo de manera rápida y superficial. Al pie de la letra: Verbo. Hacer o afirmar algo exactamente como se escuchó o dice la ley.

Al toque: Adverbio. Inmediatamente. Al momento.

Apretar los dientes: Verbo. Concentrarse. Realizar una acción con decisión y fuerza. A vuelo de pájaro: Adverbio de modo. (Acción) rápida y superficial.

Al filo de la navaja: Adverbio de modo. Al límite. Posición incómoda y peligrosa. Agarrar de cholito: Verbo. Engañaro burlarse dealguien en reiteradas oportunidades.

B

Boca a boca: Adverbio de modo. Un mismo nivel. Discusión oral acalorada.

\section{C}

Caminar pisando huevos: Adverbio de modo. Forma fingida de mostrar delicadeza o finura.

Codo a codo: Adverbio de modo. Esfuerzo conjunto de dos o más personas que pugnan por lograr algo.

Con los crespos hechos: Adjetivo. (Quedar o dejar) desairado. Frustrado.

\section{D}

De mal en peor: Adjetivo superlativo. Grave una enfermedad o situación.

\section{E}

En carne propia: Verbo. Experimentar un hecho cualquiera personalmente.

\section{I}

Ir de la mano: Verbo. Realizar una actividad de acuerdo a la situación, a la regla o ley.

Plato fuerte. En el DRAE, significa 'asunto o intervención más importante en una serie de ellos'. La función sintáctica es la de atributo. El connotado escritor venezolano será el plato fuerte en la ronda de conferencias.

Rol de motor. Frase que significa 'impulsador'. Cumple la función de objeto directo. No debemos olvidar nuestro rol de motor de la economía. 


\section{Unidades fraseológicas en el español limeño}

Laboratorio de experiencias educativas. En el DRAE, «laboratorio» significa 'realidad en la cual se experimenta o se elabora algo'. Cumple la función de atributo. El Perú debe ser un gran laboratorio de experiencias educativas.

Remover el avispero. En el DRAE, «alborotar el avispero» es una locución verbal que significa 'causar alteración y desorden en un grupo de personas'. Ideas que ciertamente removerán el avispero en Paracas.

Apagar el fuego con gasolina. Locución verbal que significa 'apaciguar alguna situación candente con un elemento inflamable', 'aumentar el problema'. Actuar con violencia ante otra violencia es como querer apagar el fuego con gasolina.

Tomar la justicia por nuestras propias manos. En el DRAE, «tomarse alguien la justicia por su mano» es una locución adverbial que significa 'aplicar por su cuenta una medida o castigo que cree merecidos'. No es conveniente tomar la justicia por nuestras propias manos.

Caer en sacos rotos. Locución verbal que significa 'no tener respuesta, caer al vacío. Las quejas y reclamos caen en sacos rotos.

Con las manos en la masa. Frase que significa 'ser sorprendido en fragante delito'. Cumple la función de complemento circunstancial de modo. Hay que atraparlos con las manos en la masa.

Volverse viral. Locución verbal que significa 'se ha difundido'. Se ha vuelto viral.

La otra cara de la moneda. Frase que significa 'lo opuesto, lo contrario'. Cumple función de objeto directo. Veamos la otra cara de la moneda.

En mancha(s). En el DRAE, «mancha» aparece como 'bandada, manada', aplicable a animales. En el contexto de la fraseología, se extiende a personas 'en grupo'. Cumple la función de complemento circunstancial del modo. Los jóvenes andan en manchas. Te has puesto de acuerdo para agarrarme en mancha.

A piedrones. En el DRAE, «pedrón» es 'aumentativo de piedra'. En la frase 'discusión fuerte'. Los jóvenes se agarran a piedrones.

A machetazos. En el DRAE, «machetazo» es el 'golpe que se da con machete'. En la frase 'hablar falsedades, con calumnias'. Cumple la función de complemento circunstancial de modo. Los morenos se agarran a machetazos.

Como dos gotas de agua. Frase que significa 'iguales, idénticos'. Cumple la función sintáctica de atributo. Somos como dos gotas de agua.

De buena familia. Frase que significa 'respetable, bien visto'. Cumple la función de atributo. Ustedes son de buena familia.

De calzoncillos finos. Significa 'de buen gusto'. Cumple la función de atributo. Somos de calzoncillos finos. 
Voz de sargento jubilado. Significa 'rudo, testarudo'. Cumple función de objeto directo. Tiene voz de sargento jubilado.

Hombre de peso. Significa 'mayor de edad'. Cumple la función de atributo. Ya no te voy a batir porque eres hombre de peso.

Apagado. Significa 'cabizbajo, triste, preocupado'. Ya pues, hermano, te veo apagado.

Prender. En el DRAE, significa 'asir, agarrar, sujetar algo'. En el ejemplo, 'molestar'. Se le ha prendido a Guillermo y tú te quedas. Ponle otra chapa también.

Quedarse. En el DRAE, significa 'dicho del viento, disminuir su fuerza'. En el ejemplo, se aplica a las personas, 'disminuir las fuerzas para decir o actuar'. Se le ha prendido a Guillermo y tú te quedas. Ponle otra chapa también.

Quedar chico. Locución verbal que significa 'poca cantidad'. Te ha quedado chico el desayuno.

Dar con palo. En el DRAE, aparece como verbo intransitivo «dar de palos», significa 'hacer sufrir un golpe o daño', 'ser tratado con dureza'. A mí me han dado con palo.

Igualado. En el DRAE, significa 'confianzudo', 'que se toma excesivas confianzas'. Oiga, no sea igualado.

Un salto al vacío. En el DRAE, 'acción de lanzarse en paracaídas desde un avión, helicóptero, etc.' En la frase, 'arriesgar sin estar seguro'. Cumple la función de objeto directo. No podemos dar un salto al vacío.

Un montón de plata. En el DRAE, «montón» se refiere a 'cantidad considerable'. En el ejemplo, significa que el padre 'es adinerado'. La frase cumple la función de objeto directo. Mi papá tiene un montón de plata.

Hermanas en el dolor. Significa 'compartir sentimientos'. Cumple función de atributo. Mi amiga y yo somos hermanas en el dolor.

Con el taco. Significa 'no de frente, disimuladamente'. Cumple función complemento circunstancial de modo. Lo digo con el taco.

A taco tendido. Significa 'bastante, mucho'. Bailaron a taco tendido.

De juerga. Significa 'de fiesta, de diversión'. Cumple función complemento circunstancial de modo. Algunos chicos se van de juerga.

Con el pétalo de una rosa. Significa 'delicadamente'. Cumple función complemento circunstancial de modo. A una mujer, ni con el pétalo de una rosa.

Mis aguas / las aguas. Significa 'beber'. Cumple función de objeto directo. A mí también me gustan mis aguas. Está preocupado por las aguas. No me subas las aguas 'no me des por borracho'. 
Como piñata. Significa 'tratar duramente'. Cumple la función de complemento circunstancial de modo. Me han dado como piñata.

Poner un polo a un pulpo. Locución verbal que significa 'dificultad extrema'. Es más difícil que poner un polo a un pulpo.

Curado de la política. Significa 'decepcionado de la política de tal manera que ya no le interesa ese tema'. Cumple la función de atributo. Estoy curado de la política.

Golpe bajo. En el DRAE, significa 'acción traicionera y malintencionada'. Cumple la función de objeto directo. Van a ver todos los golpes bajos que se dan en la política.

Tener pasado. Locución verbal que significa 'pasado negativo, de gravedad'. Tenía demasiado pasado.

Por si las moscas. Significa 'en previsión, por si acaso'. Cumple la función de complemento circunstancial de modo. Me cuido por si las moscas.

\section{Abreviaturas y símbolos utilizados}

V. Verbo o unidad verbal

Adj. Adjetivo o unidad adjetiva

Adv. Adverbio

Uf. Uso formal o estándar: «de por vida» 'para siempre'

Ui. Uso informal o sub estándar: «patas arriba» 'desordenado'

Ac. Acepciones

[ ] Encierran significados menos generales: «sacar la vuelta» 'no cumplir una ruta o una promesa', 'comprador que cambia de vendedor'.

Pol. Unidad polisémica

* Marca para indicar que es un vulgarismo: * «meter la rata» 'engañar', 'ganar haciendo trampa'

Fan. $\quad$ Frase antónima de

Fsin. Frase sinónima de 


\section{Bibliografía}

Corpas, G. (2003). Diez años de investigación en fraseología: análisis sintáctico-semánticos, contrastivos y traductológicos. España: Iberoamericana.

Lakoff, G., \& Johnson, M. (1998). Metáforas de la vida cotidiana. España: Cátedra. Llamas, C. (2005). Metáfora y creación léxica. España: Universidad de Navarra.

Penades, I. (2002). Diccionario de locuciones verbales para la enseñanza del español. España: Arco-Libros.

Penades, I. (2005). Diccionario de locuciones adverbiales para la enseñanza del español. España: Arco-Libros.

Penades, I., \& Rixiaojinghe, E. (2008). 70 refranes para la enseñanza del español. España: Arco-Libros.

Suazo, G. (1999). Abecedario de dichos y frases hechas. España: Edaf.

Varela, F., \& Kubarth, H. (1994). Diccionario fraseológico del español moderno. España: Gredos.

Zacharis, J., \& Bender, C. (1991). Comunicación oral, un enfoque racional. México: Limusa. 